\title{
Adapting cultural heritage to climate change impacts in the Netherlands: barriers, interdependencies, and strategies for overcoming them
}

\author{
Sandra Fatorić ${ }^{1}$ (D) $\cdot$ Robbert Biesbroek ${ }^{2}$
}

Received: 10 September 2019 /Accepted: 12 August 2020 /Published online: 21 August 2020

(C) The Author(s) 2020

\begin{abstract}
Climate change is currently impacting cultural heritage globally. Despite advances in the understanding of the relationship between climate change impacts and cultural heritage, there are significant barriers that hamper adaptation of cultural heritage to current and projected climate risks. This paper aims to advance the empirical understanding of barriers to adapting cultural heritage to climate-related impacts in the Netherlands by identifying different barriers, their interdependencies, and possible strategies to overcome these barriers. Using a web-based questionnaire with 57 experts, we find that the most frequently reported barriers are a lack of climate change adaptation policy for cultural heritage, and lack of climate vulnerability and risk assessments for diverse cultural heritage types. Our study finds that barriers are perceived to be interdependent and conjointly constrain adapting cultural heritage to climate change. Six actionable strategies are identified to navigate these barriers.
\end{abstract}

Keywords Climate change adaptation $\cdot$ Climate policy $\cdot$ Cultural heritage management $\cdot$ Historic preservation

Electronic supplementary material The online version of this article (https://doi.org/10.1007/s10584-02002831-1) contains supplementary material, which is available to authorized users.

Sandra Fatorić

s.fatoric@tudelft.nl

Robbert Biesbroek

robbert.biesbroek@wur.nl

1 Faculty of Architecture and the Built Environment, Delft University of Technology, Julianalaan 134, 2628 BL Delft, The Netherlands

2 Department of Social Sciences, Wageningen University \& Research, Hollandseweg 1, 6706 KN Wageningen, The Netherlands 


\section{Introduction}

Cultural heritage are tangible (e.g. monuments, historic buildings, cultural landscapes, archaeological sites, historic objects) and intangible (e.g. knowledge, performing arts, social practices, oral traditions and expressions) resources, inherited from the past and created in the course of time by the people and/or their interaction with the environment (UNESCO 2003; 2017), which today deliver a wide diversity of benefits to our societies, environments, and economies. Cultural heritage plays an important role in economic development and growth through tourism and recreation industries, including urban and rural revitalisation (Alexandrakis et al. 2019; Janssen et al. 2017; Licciardi and Amirtahmasebi 2012). For instance, in the Netherlands, $23 \%$ of all nationally significant cultural heritage located in the province of North Holland generates about half billion euros of the country's two billion euro revenue in the cultural and recreation industry (Statistics Netherlands 2019). Cultural heritage can foster cultural identity, sense of belonging, and community inclusion, which in turn can provide psycho-social support and enhance community resilience in the face of environmental and socio-economic stresses (Appler and Rumbach 2016; Ghahramani et al. 2020; Holtorf 2018). Furthermore, heritage offers evidence of past societal and environmental changes and provides capacity for learning and transferring traditional knowledge and skills to current socioeconomic or environmental contexts and challenges (Jackson et al. 2018; RCE 2018; Van Alphen 2020).

The Netherlands' Cultural Heritage Agency (RCE) is mandated to protect and preserve national tangible cultural heritage. Recently, the RCE recognised that climate change and associated heavy precipitation and flooding present serious risks to the country's cultural heritage, especially to their valuable museums and archival collections (RCE 2016). The intensities and frequencies of extreme weather events such as floods, droughts, and heatwaves are expected to increase by 2050 in the Netherlands (Van den Hurk et al. 2014). Although some cultural heritage such as historic landscapes, structures, and buildings were designed to cope with the flood-related hazards in the Netherlands (RCE 2018; Van Alphen 2020), the magnitude of projected changes and cascading risks will challenge the effectiveness of these adaptation measures in the future. This is not unique to the Netherlands; climate change already challenges cultural heritage management globally by accelerating the deterioration and loss of diverse cultural heritage types (Bosher et al. 2019; Hollesen et al. 2018; Rockman et al. 2016). Increasing resilience of cultural heritage to climate change requires proactive climate adaptation which can reduce deterioration and potential loss (Chmutina et al. 2016; Ghahramani et al. 2020; Sesana et al. 2018), while maximising heritage benefits for current and future generations (ICOMOS 2019).

Climate change adaptation of cultural heritage is a process that seeks to moderate the harm or exploit opportunities associated with current or potential future climate change impacts (IPCC 2014). Over the past three decades, climate change adaptation research, practice, and policy globally have focused on various vulnerable sectors (for a comprehensive adaptation analysis, see Lesnikowski et al. 2016), but research on adaptation of various cultural heritage types is still relatively weak (Fatorić and Seekamp 2017a; Heathcote et al. 2017; Leissner et al. 2015; Rockman et al. 2016; Tansey 2015). To date, most research has focused on developing frameworks, tools, or methods to assess climate risks and vulnerabilities of diverse cultural heritage types (Fatorić and 
Seekamp 2017a). While these studies make a crucial step in recognising climate change risks and raising awareness, there have been limited efforts to understand the design of feasible adaptation measures, and the governance challenges encountered in implementation to increase cultural heritage resilience (Dupont and Van Eetvelde 2013; Fatorić and Seekamp 2019; Xiao et al. 2019). Therefore, there is an urgent need to identify the different types of barriers that arise in the adaptation process in order to bridge the gap between climate change science and climate change adaptation planning and implementation for cultural heritage. However, to the best of our knowledge only two studies (Fatorić and Seekamp 2017c; Sesana et al. 2018) systematically identified and characterised multiple types of barriers to cultural heritage climate adaptation and strategies to overcome them.

To address this important knowledge gap, we identify, characterise, and analyse different types of barriers to adapting cultural heritage to climate change perceived by Dutch experts in the field. In particular, we are interested in understanding the interdependencies of these barriers, and possible strategies to overcome them.

The Netherlands is considered here as a typical case for countries that are adapting to climate change at different government levels. Since 2005, the Dutch government has had a holistic perspective on spatial adaptation and has briefly mentioned the role of tourism and heritage sites in their first National Adaptation Strategy (NAS) (VROM 2007). However, these plans hardly materialised in practice and with the national framework Delta Programme adopted in 2010, the focus shifted towards improving flood risk management, ensuring sufficient freshwater supply, and ensure the main economic sectors are climate-proof and water-resilient through the implemented Delta Plan on Spatial Adaptation (Delta Programme 2018). The Delta Plan on Spatial Adaptation establishes guidelines for different government levels to accelerate the spatial adaptation process. The guidelines include processes for assessing and mapping vulnerability or conducting stress tests for waterlogging, urban flooding, heat, drought, and subsidence impact; designing and mainstreaming climate adaptation in plans and regulations; and conducting a risk dialogue with citizens. Although Delta Programme recognises that existing cultural heritage is a source of inspiration for spatial development, and that cultural heritage provides knowledge from the past on how one could deal with waterand flood-related hazards (Delta Programme 2018), climate change risks to cultural heritage are not explicitly addressed. There is a similar lack of consideration in the second NAS, which in-part aims to raise public awareness of four main climate change effects unique to the country-increases in coastal and river flooding, urban pluvial flooding, drought, and heat, and respective implications for nine socio-economic sectors (IenM 2016). As with the Delta Programme, the NAS only mentions cultural heritage in passing, but advocates to develop a climate adaptation process to address risks to diverse cultural heritage assets. Similarly, RCE has yet to issue clear guidelines, institutional policies, or a regulatory framework to prepare diverse cultural heritage assets for climate change risks. Nevertheless, the new National Environmental Planning Strategy, NOVI (one of the core instruments of the upcoming Environment and Planning Act) sets out a new policy for enhancing the integrated management of various national sectors with cultural heritage preservation (BZK 2018).

The next section briefly reviews the scarce literature on barriers to climate change adaptation of cultural heritage, followed by the methodology. Section 4 presents the findings, which are discussed in Sect. 5 . 


\section{Barriers to climate change adaptation of cultural heritage}

Barriers to climate adaptation of cultural heritage can be understood as obstacles, constraints, or hurdles that delay or prevent the design or implementation of concrete actions in order to reduce vulnerability ${ }^{1}$ or increase the adaptive capacity of cultural heritage to prepare for or respond to climate change (Biesbroek et al. 2011; Eisenack et al. 2014). Barriers are the result of complex governance processes, the characteristics of the multi-level actors and nature of the system (e.g. cultural heritage) involved, and a larger governance context within which the multi-level actors and system operate (Moser and Ekstrom 2010). Barriers are shown to arise at all stages of the policy process, from framing the problem of climate change, considering response options and adaptation planning, to implementation, monitoring, and evaluation (Moser and Ekstrom 2010). Barriers are perceived and socially constructed, meaning that people interpret, reflect, and react based on their lived experience of these complex governance processes (Biesbroek et al. 2014). The consequences of perceived barriers are real, as they influence the policy actions that actors can take (Biesbroek et al. 2014).

The emerging evidence on barriers (or any of its synonyms) to climate adaptation of cultural heritage suggests that there are broadly four types of barriers: institutional, technical, socio-cultural, and financial barriers (Biesbroek et al. 2014; Fatorić and Seekamp 2017c).

First, barriers to taking adaptation action are often attributed to lack of institutional frameworks, policies, laws, and regulations, including unclear mandates (Breen 2007; Casey and Becker 2019; Fatorić and Seekamp 2017c; Kim 2011). Evidence shows that lack of guidelines and standards for adaptation to assist decisionmakers and stakeholders in selecting relevant interventions for reducing risk from climate change (Casey and Becker 2019; Fatorić and Seekamp 2017c; ICOMOS 2019; Sesana et al. 2018; Phillips 2014), and lack of prioritisation processes among numerous cultural heritage assets are institutional barriers to adaptation processes (Casey and Becker 2019; Fatorić and Seekamp 2017c; Sesana et al. 2018). Furthermore, lack of coordinated governance, limited collaboration, low levels of communication among multi-level actors and stakeholders, and the lack of awareness and sense of urgency of the intersection of cultural heritage and climate change (Chmutina et al. 2016; Fatorić and Seekamp 2017c; Henderson 2019; Phillips 2014) were found in the literature as key barriers that constrain adaptation planning and implementation for cultural heritage. Barriers to climate adaptation can also arise from factors such as lack of political commitment caused by climate change denial (Fatorić and Seekamp 2017c) or lack of trust in government for heritage preservation (Brabec and Chilton 2015).

Technical barriers such as lack of knowledge about climate change vulnerabilities and risks to diverse cultural heritage types and the associated climate change uncertainty are known to pose constraints to adaptation processes (Fatorić and Seekamp 2017c; Heathcote et al. 2017; Hollesen et al. 2018; Minguez Garcia 2019; Phillips 2014; Sesana et al. 2018; Tansey 2015). Similarly, lack of knowledge about acceptable thresholds of cultural heritage loss, and limited understanding about changes to heritage values, significance, and integrity given climate

\footnotetext{
${ }^{1}$ In this paper, vulnerability is defined as the probability of losing cultural heritage (and losses to the significance or values of cultural heritage) from climate variability or change (Fatorić and Seekamp 2017b). Vulnerability of cultural heritage is characterised by (a) its location that could be adversely affected by a climatic event (i.e. exposure), and (b) the degree to which significance or values of cultural heritage could be affected by that exposure (i.e sensitivity) (Fatorić and Seekamp 2017b). In the cultural heritage field, adaptive capacity is interrelated with human's adaptive capacity because typically heritage type/site does not have a capacity to adjust on its own (Fatorić and Seekamp 2017b; Rockman et al. 2016).
} 
change impacts (Casey and Becker 2019; Fatorić and Seekamp 2017c; Sesana et al. 2018) emerge as factors constraining adaptation. Furthermore, insufficient technical skills, training, and information access to better understand and implement adaptation measures, together with lack of best practice examples (Chmutina et al. 2016; Fatorić and Seekamp 2017c; Kim 2011; Phillips 2014) were reported to hinder adaptation planning and implementation. Limited holistic or integrated management of cultural and natural heritage is also found as a technical barrier (Fatorić and Seekamp 2017c; Henderson 2019).

Adaptation of cultural heritage is further constrained by socio-cultural factors that are linked to people's values, perceptions, and judgements, including place attachment and place dependence (Fatorić and Seekamp 2017b; Ghahramani et al. 2020; Henderson and Seekamp 2018; Sherren et al. 2016). These socio-cultural barriers influence decisions about which cultural heritage to preserve for future generations, or which adaptation measure is considered as acceptable (Fatorić and Seekamp 2017b; Henderson and Seekamp 2018; Sherren et al. 2016; Xiao et al. 2019). Lack of stakeholders' motivation and willingness to act (Sesana et al. 2018), and little appreciation of heritage (Bosher et al. 2019) also constrain cultural heritage adaptation.

Financial barriers to adaptation of cultural heritage are typically related to lack of funding for adaptation planning and implementation of specific measures, including limited tax incentives and subsidies for the maintenance of private- and public-owned cultural heritage (Fatorić and Seekamp 2017c; Henderson and Seekamp 2018; Licciardi and Amirtahmasebi 2012; Sesana et al. 2018). Additionally, limited willingness or capacity to mobilise funding for research, education, and innovation constrain adaptation policy (Breen 2007; Fatorić and Seekamp 2017c; Kim 2011).

There are increasing calls in the literature on climate change adaptation (Biesbroek et al. 2013; Eisenack et al. 2014; Wellstead et al. 2018), and specifically on climate change adaptation of cultural heritage (Fatorić and Seekamp 2017c) that identifying and listing barriers is not sufficient to provide actionable knowledge to policymakers to intervene in policy processes. Biesbroek et al. (2013) call for the need to understand not only which barriers to climate adaptation occur but also why these barriers arise, and how they are interlinked. Different types of barriers can co-occur, reinforce each other, or cause new barriers to adaptation to emerge (Oberlack 2017). A better understanding of these interdependencies can support in reducing the emergence and persistence of barriers (Eisenack et al. 2014). Previous research has suggested that barriers can be overcome with leadership, adequate resources (e.g. financial resources, technology, know-how), effective communication and information, awareness raising, and collaborations among multi-level actors (Oberlack 2017; Simonet and Leseur 2019). Yet, such perspective is hardly used in the context of cultural heritage.

\section{Material and methods}

\subsection{Data collection}

Using a web-based questionnaire, we aimed to assess different types of barriers to adaptation, their interdependencies, and identify strategies for overcoming them. A web-based questionnaire was chosen because it can be administered relatively quickly and inexpensively, and it can be more convenient for both respondents (e.g. respond when time permits, complete 
questionnaire in multiple sessions) and researchers (e.g. timeliness and efficiency of data entry and analysis). However, a limitation of the web-based questionnaire is a lack of in-person communication to immediately clarify possible questions or concerns (Evans and Mathur 2018). Web-based questionnaires are used as an effective method for exploring perceived barriers to climate change policy-making and environmental management (e.g. Biesbroek et al. 2011; Brown et al. 2009; Ezeah and Roberts 2012; Fatorić and Seekamp 2017c).

We identified 85 experts actively working in cultural heritage management and/or policy in the Netherlands through a purposive sampling ${ }^{2}$ (Bryman 2012). In this study, an expert is defined as an individual with specialised knowledge or technical expertise in cultural heritage management and/or policy in the Netherlands. We carefully selected an expert sample with a diversity of professional backgrounds and expertise (e.g. historic buildings, landscapes, structures, archaeological sites, historic objects/collections, traditional practices). The experts were also selected to represent a diverse group of stakeholders, including private sector actors, academics and researchers, non-governmental organisations, government staff from national, provincial, and municipal levels, and water authorities.

The questionnaire design builds on a similar web-based questionnaire developed by Fatorić and Seekamp (2017c), which served as a pilot study in identifying barriers to climate adaptation of cultural heritage in the USA. Using the same but improved research instrument and methods in different geographical contexts allows researchers to explore similarities and differences among settings, as well as allows to confirm external validity and generalisability of results (Bryman 2012; Polit and Beck 2010). Based on the questionnaire pre-test with three experts, the design of the questionnaire and its questionnaire items were proven to be clear and precise, while the burden of the length and complexity (e.g. the question on strategy provided three general examples) were carefully considered to achieve valid and meaningful results (Dillman et al. 2014). In this study, the term "cultural heritage types" is used to simplify the presentation of results. In this context, the term encompasses various categories or typologies of both tangible and intangible cultural heritage (as defined by UNESCO 2003, 2017). While the experts were asked about cultural heritage management, they typically provided answers related to the cultural heritage type (both tangible and intangible) they had an expertise.

Questionnaire items included were (a) four closed-ended questions about professional background and work experience of the expert, (b) three open-ended questions to assess experts' perceptions about the three greatest cultural heritage management challenges presented by a changing climate in the Netherlands, and (c) three open-ended questions to identify the three greatest strategies needed for overcoming those challenges. Open-ended questions were chosen to allow respondents to mention a wide a range of perceived barriers and strategies, as well as to reduce bias from misinterpretation, and from suggesting answers and influencing experts' perceptions (Desai and Reimers 2018). The questionnaire was made available in English and Dutch languages and administered using Qualtrics Survey Software. The English version of the questionnaire can be found as Supplementary Material (SM) 1.

The experts were contacted by email in March and April 2019. The emails included instructions and a link to complete the web-based questionnaire, information about the study's goal and objectives, structure of the online questionnaire, estimated completion time, and statement of the voluntary participation in the study. Four reminder emails were sent to non-

\footnotetext{
${ }^{2}$ The initial sample frame consisted of several members of the Water Heritage Network and Centre for Global Heritage and Development. The sample also included climate change adaptation policy expert and flood risk management expert who have some extent of experience in cultural heritage practice/policy.
} 
respondents during a one-month period. The questionnaire instrument and protocols were approved by the Human Research Ethics Committee of the Delft University of Technology. The average time needed for completion was $14 \mathrm{~min}$.

Of the 85 experts sent the initial email request, three experts replied they lacked expertise while one expert did not provide a reason for opting out. After removing three experts who did not feel qualified, the total sample size was 82. Fifty-seven experts completed the questionnaire (70\% response rate). A quarter of experts worked for the national government $(25 \%)$, followed by the private sector, non-governmental organisation and academic institution (each $16 \%)$, local government (14\%), provincial government (6.5\%), and water authority $(6.5 \%)$. Respondents covered all twelve Dutch provinces and several operated internationally. The largest number of respondents carried out their work in the province of Gelderland (12\%) which is also the largest of the Dutch provinces. Experts averaged 9 years of experience in their current position (range between 1 and 20 and more years), while their average experience working in the cultural heritage sector was 17 years (ranging from 1 and 38 years).

\subsection{Data analysis}

Forty-nine questionnaires were completed in the Dutch version, while eight questionnaires were completed using the English version of the questionnaire. The answers to questionnaires in Dutch were translated into English using Google Translator before the analysis. To validate the conceptual and technical accuracies of the translation a review of translation was carried out by a native Dutch speaker.

All responses to closed-ended questions were downloaded into Microsoft Office Excel spreadsheet for analysis using descriptive statistics.

Responses to open-ended questions were downloaded as text into ATLAS.ti 8.4.4 and coded by the lead author, then, peer debriefing was carried out by an external researcher who has expertise in climate change adaptation policy to validate the codes. As shown in Fig. 1, coding of the data comprised four stages (Saldaña 2012). First, descriptive coding was utilised to develop and categorise the main three themes of codes such as "practice challenge," "policy challenge," and "strategy or need" according to the question. Then, initial coding restructured the data and formed subthemes. We condensed content coded (subthemes) as either "policy challenge" or "practice challenge" into one main theme titled "barriers," while content coded as "strategy or need" remained unchanged. Next, axial coding was used to sort, compare and collate all the relevant coded data, and classify both the "barriers" and "strategies" subthemes as relating to one of four core categories presented in Sect. 4: "institutional," "technical," "socio-cultural," and "financial." Last, causation coding was applied to analyse relationships or interdependencies among the subthemes of barriers by analysing the frequency of relationship between two barriers and direction of the relationship (i.e. negative influence) as noted by respondents. For example, one respondent indicated that there was "...No sense of urgency about the effects of climate change on heritage. This influences inaction for designing climate adaptation policy". This was coded as an interdependency between lack of urgency and lack of climate change adaptation policy, as well as the direction of influence was defined (see Fig. 3).

Once all open-ended responses were coded, the frequency of each subtheme (i.e. each barrier and strategy) was calculated to illustrate the range of experts' opinions. Given the explorative nature of this study, we focused on descriptive statistics rather than carrying out a statistical analysis of identified barriers and strategies (Polit and Beck 2010). A sample of 


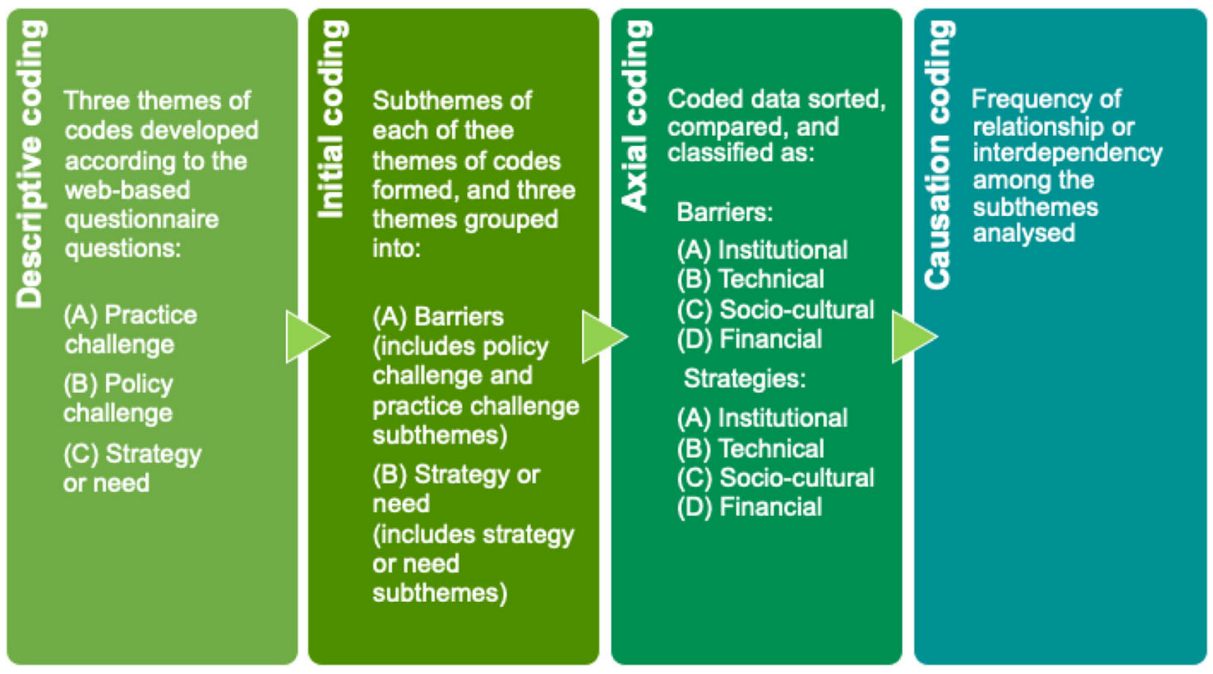

Fig. 1 Process used for qualitative data coding (Saldaña 2012)

quotations for barriers, their interdependencies, and strategies from the questionnaire is provided in SM2.

\section{Results}

In this section, the main findings organised by perceived barriers to adapting cultural heritage to climate change in the Netherlands together with possible interdependencies among barriers, and strategies to overcome them, are presented.

\subsection{Barriers to adapting cultural heritage to climate change}

Experts identified a total of 337 barriers which were synthesised into 15 distinct barrier subthemes, see Fig. 2. These subthemes are further organised in the following categories: (a) institutional barriers, (b) technical barriers, (c) socio-cultural barrier, and (d) financial barrier (Fig. 2).

\subsubsection{Institutional barriers}

The most frequently reported barrier was a lack of climate change adaptation policy for cultural heritage ( $n=97$ mentions). Experts noted that while clear national, provincial, and local institutional frameworks and policies for climate or spatial adaptation of various sectors exist, there is no specific regulation or policy for diverse cultural heritage types. This included the lack of formal technical guidelines or plans for appropriate risk-reducing climate adaptation measures that can be implemented for diverse heritage types, while considering their specific historic, socio-cultural, economic, and environmental aspects. As such, experts stated that government levels do not provide enough (detailed) guidelines on how and what to do given climate change impacts, especially related to the experienced increase in summer drought and heavy precipitation. Respondents noted that decisionmakers often have difficulties in the 


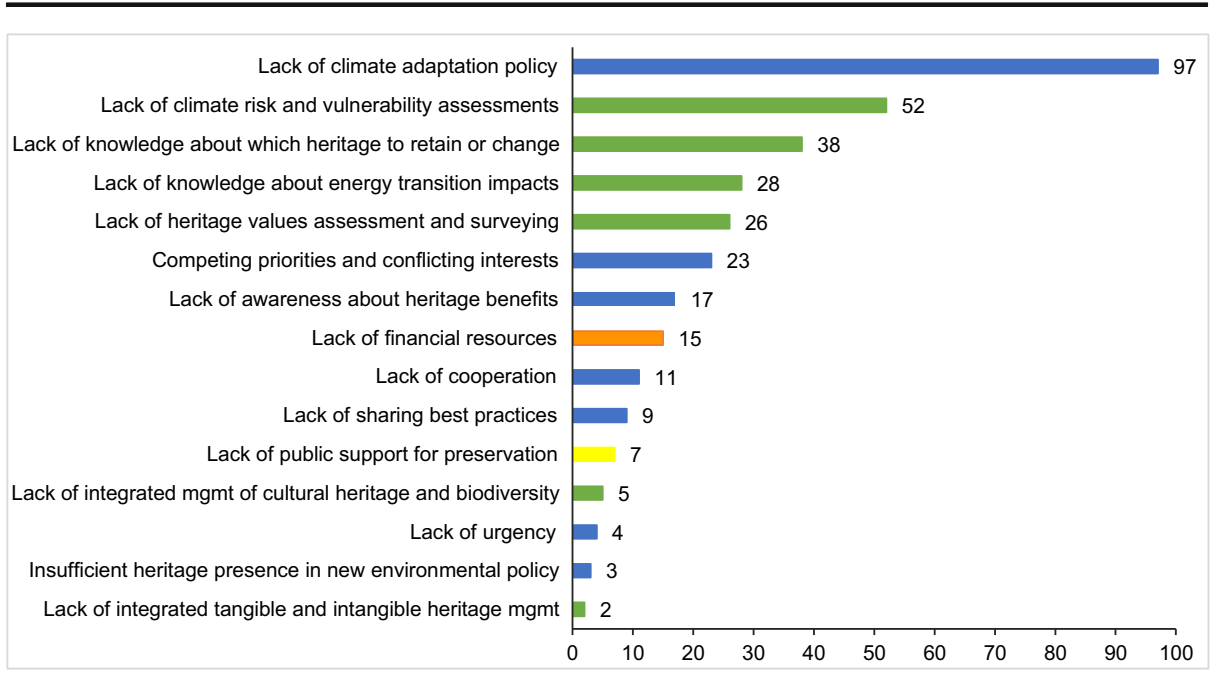

Fig. 2 Frequency of mentions for institutional barriers (in blue), technical barriers (in green), socio-cultural barrier (in yellow), and financial barrier (in orange) to adapting cultural heritage to climate change in the Netherlands $(n=337)$

identification and understanding of the technical and social feasibility of adaptation measures. It was reported that despite growing climate risk concerns, a "one-size-fits-all" approach applied in flood risk management is likely an unsuitable approach for diverse cultural heritage types because it may fail to address the site-specific climate risks to integrity and significance of cultural heritage site. The lack of adaptation policies was also noted to affect the prioritisation of heritage across various sectors and makes it difficult to understand the current and future scale of needed adaptation interventions. Furthermore, some experts indicated that spatial development and flood management have been exerting pressures, for example through changes in land use planning that exposed cultural heritage to additional risks. Another barrier linked to the policy was a difficulty mainstreaming cultural heritage into existing spatial and/or climate change adaptation policies such as National Adaptation Strategy or Delta Plan on Spatial Adaptation. Some experts commented that measures to reduce risks to cultural heritage are also largely overlooked in emergency preparedness and response.

Competing priorities and conflicting interests $(n=23)$ is another institutional barrier impeding efficient policy efforts that could incentivise climate adaptation at multi-level governance scales. Experts reported challenges arising from conflicts of interests between different sectors and land uses (e.g. dyke safety improvements leading to cultural landscape or archaeological degradation or loss), and lack of priority-setting and relevance of cultural heritage preservation to all government levels and a wide range of stakeholders. Experts argued that trade-offs resulting from climate-proofing one sector over the cultural heritage sector may become more common in the future, which could cause valuable and irreplaceable cultural heritage to be lost.

A lack of awareness of cultural heritage benefits $(n=17)$ particularly among stakeholders and policymakers from environmental and climate change fields was perceived as an institutional barrier that can constrain the development of climate adaptation policy for cultural heritage. Experts stressed that while cultural heritage can promote economic growth, contribute to sustainable development and climate change mitigation, and provide the inspiration and knowledge for current and future climate adaptation planning, little has been done to integrate 
cultural heritage values, benefits, and opportunities into environmental and climate decisionmaking or policy-making processes at different government levels.

Results also suggest that impediments that arise from the lack of awareness are related to the perceived lack of cooperation $(n=11)$ and lack of sharing best practices $(n=9)$ between cultural heritage and environmental stakeholders. Experts noted that there is insufficient crosssectoral communication of current and planned actions, including a limited transfer of best practices of heritage opportunities (e.g. the contribution of heritage to science and technology and water management) that could inform current and future environmental and climate change decision-making processes.

A few experts mentioned that a lack of urgency $(n=4)$ constrains the current development of comprehensive measurement tools for climate change risks to diverse cultural heritage types, together with the development of climate adaptation policy for cultural heritage. This barrier also reflects the insufficient cultural heritage presence in new environmental policy (NOVI) $(n=3)$. Experts expressed concern that the new policy is predominantly focused on long-term challenges of various sectors where diverse cultural heritage types are poorly integrated into these sectors, and with poor consideration of heritage as a guiding principle for the environmental or spatial planning.

\subsubsection{Technical barriers}

Results show that a second frequently reported barrier was a lack of climate change risks and vulnerability assessments for diverse cultural heritage types $(n=52)$. Specifically, experts opined that a lack of models and tools that can assess the current and future level of risk, exposure to risks, potential impact of loss, and probability of climate-related impacts on diverse cultural heritage types create a technical barrier. Land subsidence, and increasing frequency and duration of summer drought were mentioned as the most challenging environmental or climate-related impacts affecting wooden foundations of historic buildings, cultural landscapes features, archaeological site materials, and safety of historic structures (e.g. water canals and dykes). Interestingly, flood-related risks such as changes in river discharge, heavy rainfall, and sea level rise were perceived as less challenging climate-related impacts on current cultural heritage management. Furthermore, experts indicated that although the Netherlands has a long tradition of knowledge and research development in flood risk mitigation, this has not been widely applied to diverse cultural heritage types. Experts also commented that the lack of tools to conduct stress tests for diverse cultural heritage types impedes a climateresilient management.

A lack of knowledge about which cultural heritage to retain and change $(n=38)$ reflects the fact that due to the relatively high maintenance cost of government and owners, and government's priorities in reducing climate change impacts to "vital and vulnerable functions" [key sectors], not all current cultural heritage types and associated values may be retained in current form and adapted for the future. For instance, while experts perceived that climate change already imposes an economic burden on heritage management, lack of rigorous methodological approaches for making more transparent decisions about which cultural heritage to preserve in current form (and values), and which heritage to change or give a new operational function (e.g. renewable energy transition, adaptive reuse for reducing maintenance cost) are lacking. Furthermore, experts noted that sustainability in heritage management is an emerging issue, but they raised the issue of limited capacity to understand how to enhance the sustainability of 
diverse heritage types through cost-effective materials and more sustainable construction techniques.

Experts also documented a lack of knowledge about the impacts of energy transition on cultural heritage $(n=28)$ as a technical barrier, particularly given climate change risks. Even though this barrier is related to climate change mitigation rather than adaptation, experts expressed a concern about a lack of clarity or knowledge how new technically-oriented interventions for energy generation (e.g. wind turbines, solar panels) may affect, transform, and shape authenticity, values, functions, and spatial appearance (quality) of diverse cultural heritage types (implications for cultural landscapes were most often mentioned). Some experts, on the other hand, mentioned that the transition towards a circular economy and renewable energy system can provide new opportunities and functions for cultural heritage, for instance, reusing historic structures (e.g. canals) for water retention purposes can contribute to climate adaptation efforts.

A lack of heritage values assessment and surveying $(n=26)$ was perceived as a barrier that impedes climate adaptation of cultural heritage. Experts pointed out that there are currently limited measurement tools and approaches for assessing diverse cultural heritage values, especially the ones related to cultural and historical aspects in the case of both slow onset (e.g. sea level rise) or rapid onset climate events (e.g. flooding). Experts noted that this barrier not only applies to a climate change context but also to impacts from vandalism, tourism, inefficient use of existing heritage, and spatial development. Additionally, a lack of comprehensive surveying and monitoring techniques and methodologies that could improve the effectiveness of vulnerability and impact assessments within existing spatial planning and flood risk management for archaeological sites are noted as technical barrier. Some experts also reported that innovation in the cultural heritage field is lacking.

A few experts considered a lack of integrated management of cultural heritage and biodiversity $(n=5)$ as a barrier, which reflects a weak cross-sectoral dialogue that can adversely affect a natural part of cultural landscapes such as habitats and biological diversity. Moreover, experts mentioned that a lack of integrated intangible and tangible heritage management $(n=2)$ constrains the development of a common agenda for sustainable management and climate adaptation of cultural heritage.

\subsubsection{Socio-cultural barriers}

A lack of public support $(n=7)$ was perceived as a socio-cultural barrier to adapting cultural heritage to climate change impacts. Experts also noted that despite a longstanding flood riskrelated knowledge, history, and governance in the Netherlands, there is a lack of public engagement and co-creation approach, motivation, and support for adapting diverse cultural heritage types against current and future climate change risks.

\subsubsection{Financial barriers}

The experts perceived a lack of financial resources $(n=15)$ as a factor constraining current cultural heritage management for adapting to climate change impacts. Experts expressed a limited finance mobilisation for climate adaptation of diverse heritage types, especially considering the increasing costs of climate-related impacts among other sectors, together with a lack of long-term investment roadmap for cultural heritage. A lack of financing structures and subsidies for private owners of historic buildings/monuments to effectively cope with 
climate change, and aligning finance with sustainability were also mentioned as financial barriers. A few experts mentioned that they have difficulties factoring climate change into current funding procedures for cultural heritage management, including insufficient funding for research and technology related to climate change and cultural heritage intersection.

\subsection{Interdependencies among barriers}

Figure 3 shows the reported negative influences among the different barriers to adapting cultural heritage to climate change. Two types of negative influences (directions) among the barriers were identified: (a) external direction where the barrier of one category can influence the barrier in another category (e.g. a lack of urgency influences a lack of climate risk and vulnerability assessments) and (b) internal direction where the barrier of one category can influence another barrier within the same category (e.g. a lack of urgency influences a lack of climate change adaptation policy). These interdependencies and their directions were identified from experts' responses using a causation coding technique. Note that only interdependencies

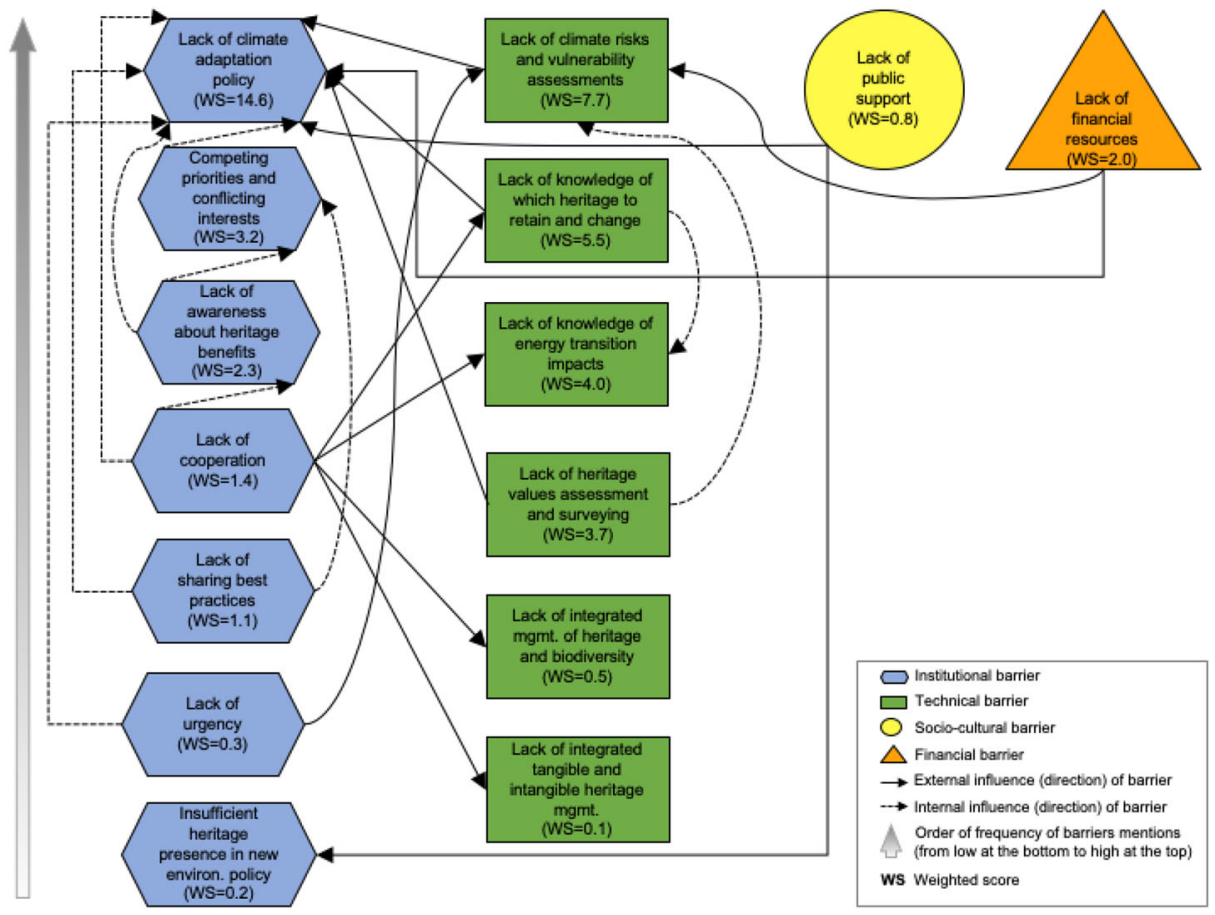

Fig. 3 Visualisation of interdependencies among barriers to adapting cultural heritage to climate change in the Netherlands as indicated by the experts. Institutional barriers are shown in blue hexagons, technical barriers are in green squares, financial barrier is in orange triangle, and socio-cultural barrier is in yellow circle. Each barrier also shows a weighted score (WS). This score was calculated by first normalising a frequency of mentions of each barrier (to allow for direct comparisons across the different barriers), and then equal weighting (0.067 weight for each barrier) was applied so that each barrier receives a final weighted score. A higher WS indicates greater importance, e.g. lack of climate adaptation policy (WS =14.6) is roughly twice as important as lack of climate risks and vulnerability assessments (WS $=7.7$ ). The black solid arrows show external influence (direction) on other barriers, while black dashed arrows show the internal direction of interdependencies with other barriers. The grey arrow shows the order of frequency of barriers mentions (from the least mentioned at the bottom to the most mentioned at the top) 
and their direction of influences identified in the expert questionnaire are visualised, however, we recognise that there may be other interdependencies among identified barriers.

Our results show that the identified barriers are dynamically interdependent and are not mutually exclusive. The most frequently mentioned barriers by the experts such as lack of climate adaptation policy, lack of climate risk and vulnerability assessments, and lack of knowledge about which cultural heritage to retain and change appear to be intertwined. For instance, insufficient knowledge about climate risks and vulnerability, and limited knowledge about which heritage types to preserve and adapt or transform, can hinder climate change adaptation policy for cultural heritage. Similarly, limited funding together with weak public support or motivation for acting on adaptation, as well as competing and conflicting priorities among sectors, and poor awareness of heritage benefits for a wide range of sectors can constrain climate adaptation policy. Another example is lack of cooperation, which can be a limiting factor, especially for technical barriers, such as the lack of knowledge about which cultural heritage to retain and change, lack of integrated management of cultural heritage and biodiversity, lack of integrated intangible and tangible heritage management, lack of knowledge about the impacts of the energy transition on cultural heritage, as well as for some institutional barriers such as lack of sharing best practices, and lack of awareness of cultural heritage benefits.

\subsection{Strategies for overcoming identified barriers}

When asked about the possible ways to overcome the barriers to adapting cultural heritage to climate change, experts identified 185 different strategies, which were synthesised into six main subthemes (Fig. 4).

The main strategy reported to overcome some of the barriers identified by the experts is the development of cultural heritage climate adaptation policy $(n=64)$. Experts stressed that developing an enabling legal, institutional, and operational framework for climate adaptation of cultural heritage, or mainstreaming cultural heritage both within and across existing climate and spatial adaptation policies at all government levels in order to bridge institutional silos and enhance coordination among relevant institutions and actors is of great importance for

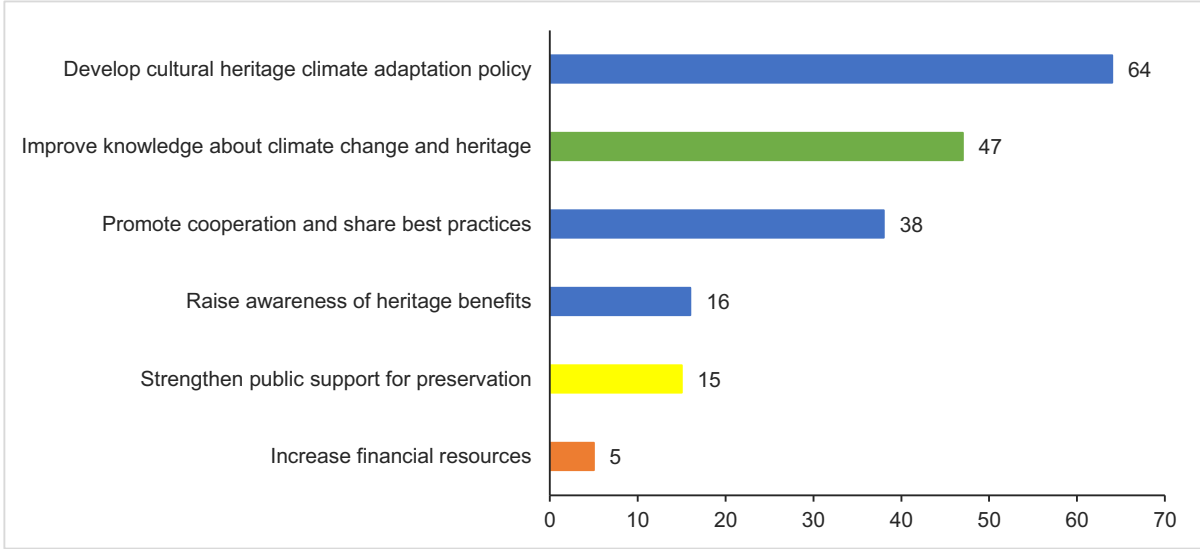

Fig. 4 Frequency of mentions for institutional strategies (in blue colours), technical strategy (in green), sociocultural strategy (in yellow), and financial strategy (in orange) to adapting cultural heritage to climate change in the Netherlands $(n=185)$ 
overcoming some of the institutional and technical barriers. Attention to integration and mainstreaming can strengthen the position of cultural heritage adaptation vis a vis other competing priorities. Experts also opined that as the socio-economic and environmental pressures on cultural heritage are increasing, cost-effective cultural heritage strategies are needed. These strategies need to focus on current and future preservation targets in terms of concepts, indicators for monitoring heritage change, and a new range of feasible maintenance and preservation options need to be integrated with relevant environmental and climate change guidance and policy.

An improved knowledge about climate change and cultural heritage $(n=47)$ was perceived by the experts as a strategy that is vital to preserving cultural heritage for present and future generations. Specifically, experts identified an urgent need to improve scientific understanding of current and future climate risks and vulnerabilities to diverse cultural heritage types, as well as to develop concrete regional climate change scenarios. A few experts stated that enhancing the practical-oriented and collaborative problem-solving academic education, together with improved communication of risk information tailored to a wide range of stakeholders is needed for more efficient management of cultural heritage given climate change impacts. Furthermore, experts frequently highlighted the need to focus not only on providing more and a better longterm climate change data, but also to focus on analytical tools, and new technologies that can more transparently and jointly characterise new and evolving cultural heritage values, qualities, and functions, including the integration of cultural heritage values with climate change risk assessments.

Promoting cooperation and sharing best practices $(n=38)$ across all government levels and diverse stakeholders was identified as a critical strategy. Experts argued that promoting and strengthening cooperation among environmental/climate and cultural heritage stakeholders and multi-level actors is needed for more flexible and effective cultural heritage management facing a changing climate. Additionally, experts stated that identifying and disseminating best practices of cultural heritage across policy domains can facilitate learning and create a body of knowledge about cultural heritage resilience, past management solutions, and techniques to cope with the current climate and environmental changes, inspire non-heritage sectors and policymakers to learn about creative ways to reduce climate change impacts, and minimise damages and losses of diverse heritage.

Raising the awareness of the economic, environmental, and socio-cultural benefits $(n=16)$ that diverse types of cultural heritage provide to other sectors was perceived as an important precondition for current and future environmental and spatial decision-making, and for mainstreaming cultural heritage into current adaptation efforts. The necessity to raise awareness of the potential of historic buildings and structures for sustainable economic development (e.g. foster adaptive reuse and economic viability), to strengthen the role of heritage in environmental planning and spatial development, and to promote combinations of scientific knowledge and traditional or local knowledge that is embodied in cultural landscapes and historic structures, were perceived by the experts as important means to overcoming some of the main institutional barriers (lack of climate adaptation policy and competing priorities and conflicting interests).

Improving public support $(n=15)$ for cultural heritage protection and climate adaptation, including a better appreciation of diverse heritage types, and joint evaluation of values of diverse cultural heritage types (also referred to as co-creation) were perceived as needed sociocultural strategy. Experts argued that involvement and discussion with a wide range of stakeholders, private owners, and policymakers should form the basis for an informed 
decision-making process on how to deal with the changing climate and changing cultural heritage values and functions (e.g. redesign and transformation of heritage) in both short and longer terms.

Interestingly, an increase in funding $(n=5)$ was ranked as a comparatively less needed strategy for adapting cultural heritage to climate change. A few experts noted that it is necessary to increase subsidies for private owner,s and stimulating public and private funding streams for sustainable preservation, as well as to increase research grants for investigating climate change risks and cultural heritage adaptation interventions.

\section{Discussion and conclusions}

Despite progress in implementing a suite of climate adaptation policies, adaptation responses for cultural heritage in the Netherlands remain insufficiently addressed (Delta Programme 2018; IenM 2016). Our study is based on a purposive expert sample and, as such, the results should be treated carefully, however, our empirical study demonstrates which configuration of barriers experts perceive, and how barriers influence and shape each other in hampering progress on climate change adaptation in the cultural heritage sector in the Netherlands. Based on the expert input, we also offer insights on possible strategies to overcome those barriers. In doing so, we build on recent claims that developing effective climate change adaptation policies requires going beyond the recognition that barriers exist, towards an improved understanding of their interdependencies and causal mechanisms that are responsible for generating a certain governance process or outcome (Biesbroek et al. 2014, 2017; Wellstead et al. 2018). Moreover, this study responds to the calls (Fatorić and Seekamp 2017c; Sesana et al. 2018) to further investigate barriers and their interdependencies in climate adaptation of cultural heritage in wider regional and international contexts. Several remarks about the findings can be made.

Our findings suggest that adapting cultural heritage to climate change in the Netherlands is impeded by predominantly institutional and technical barriers, with less emphasis placed on socio-cultural and financial barriers. Studies from other geographical contexts (Casey and Becker 2019; Chmutina et al. 2016; Fatorić and Seekamp 2017c; Kim 2011; Sesana et al. 2018; Tansey 2015) also found that undertaking climate adaptation actions is constrained by institutional barriers such as limited institutional frameworks, standards, and technical guidelines for adaptation; lack of established adaptation prioritisation processes; weak collaboration among multi-level actors and stakeholders; and competing priorities among sectors. Failing to overcome these institutional barriers means that risks from climate change may be ignored, or even exacerbated in existing cultural heritage management practices. A better understanding of the climate change impacts and adaptation of cultural heritage, and building institutional frameworks is also critical for other sectors that are already adapting and where the adaptation measures implemented could have negative trade-offs for cultural heritage. Climate adaptation policies for cultural heritage in countries such as Ireland (CHG 2019), Italy (Minambiente 2017), and Sweden (RAA 2019) consider managing acceptable changes over time, deal with respecting and enhancing heritage values and benefits, as well as promote discourse, transparency, accountability, and adaptive learning over time. In moving forward, cultural heritage could be mainstreamed into existing adaptation policies, which could increase the efficiency of adaptive responses, reduce competing priorities, and maximise co-benefits between different policies. Mainstreaming could also serve as a way to encourage co-learning and sharing best 
practices among multi-level actors and diverse stakeholders (Runhaar et al. 2018), which can support overcoming some institutional barriers. In doing so, we encourage policymakers to ensure multi-disciplinary and collaborative approaches to increase transparency and equity in site-specific adaptation efforts (Bosher et al. 2019; Brabec and Chilton 2015; Douglas-Jones et al. 2016; ICOMOS 2019; Minguez Garcia 2019; Phillips 2014).

Adaptation of cultural heritage requires also overcoming technical barriers such as limited understanding of current and future climate change vulnerability and risks to diverse heritage types. We recommend that decisionmakers and policymakers consider the development of targeted and site-specific vulnerability and risk assessments that are sensitive to the characteristics of heritage types, and specific heritage values as a starting point of the adaptation process. As such, we agree along with other scholars (Daly 2014; Day et al. 2019; Fatorić and Seekamp 2017b; Hollesen et al. 2018; Vojinovic et al. 2016; Xiao et al. 2019) that vulnerability or risk assessments need to move beyond assessing only exposure to climate change risks, and integrate the assessment of heritage sensitivity (e.g. physical condition, structural stability, previous maintenance), heritage relative importance (heritage values or significance), and range of feasible climate adaptation measures. Furthermore, while Dutch cultural heritage policy recognises that it is not always functionally and financially feasible to preserve cultural heritage unchanged (RCE 2013), experts noted that they lack rigorous methodological approaches for making transparent decisions about which cultural heritage to preserve in current form, and which heritage to change or give a new function. Renes et al. (2019) expressed the need to explore how to ensure that cultural heritage remains in use without losing its heritage integrity, significance, and values for current and future generations. Importantly, decisionmaking processes need to involve preferences, priorities, and values of different stakeholder and community groups who could be affected by those decisions (Dawson et al. 2020; Henderson 2019; Henderson and Seekamp 2018; Fatorić and Seekamp 2018). Beyond understanding new and evolving cultural heritage values and functions, experts noted that there is a need to better develop measurement frameworks and approaches to assess diverse cultural heritage values in the case of a changing climate. Cultural heritage conservation standards, such as the constructs of authenticity and integrity will need to be rethought, and alternative ways and means of sustaining the significance or values of heritage sites may evolve (Douglas-Jones et al. 2016; ICOMOS 2019).

Despite the fact that the lack of financial resources was found in this study as a less limiting factor for adapting cultural heritage to climate change in the Netherlands, it is likely to emerge in later stages of the process, i.e. implementing adaptation actions (Moser and Ekstrom 2010). As financial resources are finite and the scale of the changing environment and climate large, some developed countries such as the UK (Dawson et al. 2020) and the USA (Fatorić and Seekamp 2019; Rockman et al. 2016) have started to deal with decisions on the extent to which can they afford to adapt cultural heritage to climate change, and how to address an associated loss of heritage. In these contexts, it was argued that building and strengthening collaboration among diverse stakeholder and community groups, supporting climate change advocates within governments and among communities, and presenting a strong case that public and private investments in climate adaptation of cultural heritage can yield benefits for society, economies and environment could lessen the financial barrier, and help to promote climate adaptation action (Graham et al. 2017; Heathcote et al. 2017; Hollesen et al. 2018).

While our study focuseson the Netherlands, many of the identified institutional, technical, socio-cultural, and financial barriers can be similar in other developed and developing country contexts. Arguably, both their relative importance (weights among barriers, see Fig. 3) and the 
configuration of interdependencies could be perceived differently. For example, we found that in the Netherlands, financial barrier was perceived as less important barrier, while Fatorić and Seekamp 2017c showed that in the USA, financial barrier was perceived as the third salient barrier. Such contextualised understanding is critical to upscale and outscale findings.

Next steps might involve exploring in-depth process tracing (i.e. a method for tracing causal mechanisms using within-case analysis of how a causal process plays out) studies of cases where adaptation is attempted to uncover the causal processes that enable or constrain a more resilient cultural heritage (Biesbroek et al. 2017; Wellstead et al. 2018). When a larger number of cases become available, comparative methods such as qualitative comparative analysis (Rihoux and Ragin 2009) can help to uncover pathways of necessary and sufficient conditions that determine the successful adaptation of diverse cultural heritage types. Future research work would also benefit from examining how and why barriers emerge and persist including the causal processes among broader stakeholder and multi-actor groups using a deliberative process. In the meantime, the characteristics of multi-type barriers, configuration of their interdependencies, and strategies identified in our study can provide important insights for both climate adaptation and cultural heritage policy-making in the Netherlands, and our approach can be upscaled globally.

Acknowledgments The research presented in this paper was supported by the European Union's Horizon 2020 Research and Innovation Programme under the Marie Skłodowska-Curie grant agreement No. 707404. We would like to thank the experts who participated in this study for sharing their opinions and time, as well as colleagues who helped identify an initial expert group: Mara de Groot from the Centre for Global Heritage and Development, and Alette van den Hazelkamp and Colette Cramer from the Water Heritage Network. We would also like to thank Dr. Linde Egberts for developing a Dutch version of the questionnaire, and for her insights on the previous version of this paper.

Open Access This article is licensed under a Creative Commons Attribution 4.0 International License, which permits use, sharing, adaptation, distribution and reproduction in any medium or format, as long as you give appropriate credit to the original author(s) and the source, provide a link to the Creative Commons licence, and indicate if changes were made. The images or other third party material in this article are included in the article's Creative Commons licence, unless indicated otherwise in a credit line to the material. If material is not included in the article's Creative Commons licence and your intended use is not permitted by statutory regulation or exceeds the permitted use, you will need to obtain permission directly from the copyright holder. To view a copy of this licence, visit http://creativecommons.org/licenses/by/4.0/.

\section{References}

Alexandrakis G, Manasakis C, Kampanis NA (2019) Economic and societal impacts on cultural heritage sites, resulting from natural effects and climate change. Heritage 2(1):279-305

Appler D, Rumbach A (2016) Building community resilience through historic preservation. J Am Plan Assoc 82(2):92-103

Biesbroek GR, Termeer CJAM, Klostermann JEM, Kabat P (2011) Barriers to climate change adaptation in the Netherlands. Climate Law 2:181-199

Biesbroek GR, Klostermann J, Termeer C, Kabat P (2013) On the nature of barriers to climate change adaptation. Reg Environ Chang 13:1119-1129

Biesbroek GR, Termeer CJ, Klostermann JE, Kabat P (2014) Rethinking barriers to adaptation: mechanismbased explanation of impasses in the governance of an innovative adaptation measure. Glob Environ Chang 26:108-118

Biesbroek GR, Dupuis J, Wellstead A (2017) Explaining through causal mechanisms: resilience and governance of social-ecological systems. Curr Opin Environ Sustain 28:64-70 
Bosher L, Kim D, Okubo T, Chmutina K, Jigyasu R (2019) Dealing with multiple hazards and threats on cultural heritage sites: an assessment of 80 case studies. Disaster Prev Manage 29(1):109-128

Brabec E, Chilton E (2015) Toward an ecology of cultural heritage. Chang Over Time 5(2):266-285

Breen C (2007) Advocacy, international development and world heritage sites in sub-Saharan Africa. World Archaeol 39(3):355-370

Brown R, Farrelly M, Keath N (2009) Practitioner perceptions of social and institutional barriers to advancing a diverse water source approach in Australia. Int J Water Resour D 25:15-28

Bryman A (2012) Social research methods, 4th edn. Oxford University Press, Oxford

Casey A, Becker A (2019) Institutional and conceptual barriers to climate change adaptation for coastal cultural heritage. Coast Manage 47(2):169-188

Chmutina K, Jigyasu R, Bosher LS (2016) Understanding the impacts of climate change on cultural heritage buildings: a case of York, UK. CIB World Building Congress: intelligent built environment for life, Tampere, Finland, May 30-Jun 3, pp 188-198

Daly C (2014) A framework for assessing the vulnerability of archaeological sites to climate change: theory, development, and application. Conserv Manage Archaeol Sites 16(3):268-282

Dawson T, Hambly J, Kelley A, Lees W, Miller S (2020) Coastal heritage, global climate change, public engagement, and citizen science. PNAS 117(15):8280-8286

Day JC, Heron SF, Markham A, Downes J, Gibson J, Hyslop E, Jones RH, Lyall A (2019) Climate risk assessment for heart of Neolithic Orkney World Heritage property: an application of the climate vulnerability index. Historic Environment Scotland, Edinburgh

Delta Programme (2018) Delta Programme 2019: continuing the work on the delta: adapting the Netherlands to climate change in time. Delta Programme Commissioner, The Hague

Department of Culture, Heritage and the Gaeltacht, CHG (2019) Built \& Archaeological Heritage Climate Change Sectoral Adaptation Plan, Prepared under the National Adaption Framework. https://www.chg.gov. ie/heritage/climate-change/the-built-and-archaeological-heritage-climate-change-sectoral-adaptation-plan/ Accessed 27 April 2020

Desai CS, Reimers S (2018) Comparing the use of open and closed questions for web-based measures of the continued-influence effect. Behav Res Methods 51:1426-1440

Dillman DA, Smyth JD, Christian LM (2014) Internet, mail, and mixed-mode surveys: the tailored design method, 4th edn. John Wiley \& Sons, Hoboken

Douglas-Jones R, Hughes JJ, Jones S, Yarrow T (2016) Science, value and material decay in the conservation of historic environments. J Cult Herit 21:823-833

Dupont L, Van Eetvelde V (2013) Assessing the potential impacts of climate change on traditional landscapes and their heritage values on the local level: case studies in the Dender basin in Flanders, Belgium. Land Use Policy 35:179-191

Eisenack K, Moser SC, Hoffmann E, Klein RJT, Oberlack C, Pechan A, Rotter M, Termeer CJAM (2014) Explaining and overcoming barriers to climate change adaptation. Nat Clim Chang 4:867-872

Evans JR, Mathur A (2018) The value of online surveys: a look back and a look ahead. Internet Res 28(4):854 887

Ezeah C, Roberts CL (2012) Analysis of barriers and success factors affecting the adoption of sustainable management of municipal solid waste in Nigeria. J Environ Manag 103:9-14

Fatorić S, Seekamp E (2017a) Are cultural heritage and resources threatened by climate change? A systematic literature review. Clim Chang 142(1):227-254

Fatorić S, Seekamp E (2017b) Evaluating a decision analytic approach to climate change adaptation of cultural resources along the Atlantic Coast of the United States. Land Use Policy 68:254-263

Fatorić S, Seekamp E (2017c) Securing the future of cultural heritage by identifying barriers to and strategizing solutions for preservation under changing climate conditions. Sustainability 9:2143

Fatorić S, Seekamp E (2018) A measurement framework to increase transparency in historic preservation decision-making under changing climate conditions. J Cult Herit 30:168-179

Fatorić S, Seekamp E (2019) Knowledge co-production in climate adaptation planning of archaeological sites. J Coast Conserv 23(3):689-698

Ghahramani L, McArdle K, Fatorić S (2020) Minority community resilience and cultural heritage preservation: a case study of the Gullah Geechee community. Sustainability 12:2266

Graham E, Hambly J, Dawson T (2017) Scotland's eroding heritage: a collaborative response to the impact of climate change. Archaeol Rev Camb 32(2):141-115

Heathcote J, Fluck H, Wiggins M (2017) Predicting and adapting to climate change: challenges for the historic environment. Hist Environ Policy 8(2):89-100

Henderson J (2019) Oceans without history? Marine cultural heritage and the sustainable development agenda. Sustainability $11: 5080$ 
Henderson M, Seekamp E (2018) Battling the tides of climate change: the power of intangible cultural resource values to bind place meanings in vulnerable historic districts. Heritage 1(2):220-238

Hollesen J, Callanan M, Dawson T, Fenger-Nielsen R, Friesen TM, Jensen AM, Markham A, Martens VV, Pitulko VV, Rockman M (2018) Climate change and the deteriorating archaeological and environmental archives of the Arctic. Antiquity 92(363):573-586

Holtorf C (2018) Embracing change: how cultural resilience is increased through cultural heritage. World Archaeol 50(4):639-650

Intergovernmental Panel on Climate Change, IPCC (2014) IPCC Fifth Assessment Report: Climate Change 2014, Working Group II: Impacts, Adaptation and Vulnerability. Cambridge University Press, Cambridge

International Council on Monuments and Sites, ICOMOS (2019) Future of our pasts: engaging cultural heritage in climate action. ICOMOS, Paris

Jackson R, Dugmore AJ, Riede F (2018) Rediscovering lessons of adaptation from the past. Glob Environ Chang $52: 58-65$

Janssen J, Luiten E, Renes H, Stegmeijer E (2017) Heritage as sector, factor and vector: conceptualizing the shifting relationship between heritage management and spatial planning. Eur Plan Stud 25:1654-1672

Kim H-E (2011) Changing climate, changing culture: adding the climate change dimension to the protection of intangible cultural heritage. Int J Cult Prop 18:259-290

Leissner J, Kilian R, Kotova L, Jacob D et al (2015) Climate for culture: assessing the impact of climate change on the future indoor climate in historic buildings using simulations. Herit Sci 3(1):38

Lesnikowski A, Ford J, Biesbroek R, Berrang-Ford L, Heymann J (2016) National-level progress on adaptation. Nat Clim Chang 6(3):261-264

Licciardi G, Amirtahmasebi R (2012) The economics of uniqueness: investing in historic city cores and cultural heritage assets for sustainable development. World Bank, Washington, DC

Minguez Garcia B (2019) Resilient cultural heritage: from global to national levels-the case of Bhutan. Disaster Prev Manage 29(1):36-46

Ministry of Housing, Spatial Planning and the Environment, VROM (2007) Maak Ruimte voor Klimaat! Nationale Adaptatie Strategie, De beleidsnotitie. VROM, The Hague

Ministry of Infrastructure and the Environment, IenM (2016) Adapting with ambition: National Climate Adaptation Strategy 2016 (NAS). IenM, The Hague

Ministry of the Environment, Land and Sea, Minambiente (2017) Strategia Nazionale di Adattamento ai Cambiamenti Climatici. Minambiente, Rome

Ministry of the Interior and Kingdom Relations, BZK (2018) Scope and Level of Detail SEA National Environmental Planning Strategy. BZK, The Hague

Moser SC, Ekstrom JA (2010) A framework to diagnose barriers to climate change adaptation. Proc Natl Acad Sci 107(51):1-6

Oberlack C (2017) Diagnosing institutional barriers and opportunities for adaptation to climate change. Mitig Adapt Strateg Glob Change 22:805-838

Phillips H (2014) Adaptation to climate change at UK world Heritage sites: Progress and challenges. Hist Environ Policy 5:288-299

Polit DF, Beck CT (2010) Generalization in quantitative and qualitative research: myths and strategies. Int J Nurs Stud 47:1451-1458

RCE (2013) Visie, Missie en Strategie. RCE, Amersfoort

RCE (2016) Risk management for collections. RCE, Amersfoort

RCE (2018) Manual water, heritage and environment. RCE, Amersfoort

Renes H, Centeri C, Kruse A, Kučera Z (2019) The future of traditional landscapes: discussions and visions. Land 8(6):98

Rihoux B, Ragin CC (2009) Configurational comparative methods. Qualitative comparative analysis (QCA) and related techniques. Sage, Thousand Oaks

Rockman M, Morgan M, Ziaja S, Hambrecht G, Meadow A (2016) Cultural resources climate change strategy. National Park Service, Washington, DC

Runhaar H, Wilk B, Persson Å, Uittenbroek C, Wamsler C (2018) Mainstreaming climate adaptation: taking stock about "what works" from empirical research worldwide. Reg Environ Chang 18(4):1201-1210

Saldaña J (2012) The coding manual for qualitative researchers, 2rd edn. Sage, Thousand Oaks

Sesana E, Gagnon AS, Bertolin C, Hughes J (2018) Adapting cultural heritage to climate change risks: perspectives of cultural heritage experts in Europe. Geosciences 8:305

Sherren K, Loik L, Debner JA (2016) Climate adaptation in 'new world' cultural landscapes: the case of Bay of Fundy agricultural dykelands (Nova Scotia, Canada). Land Use Policy 51:267-280

Simonet G, Leseur A (2019) Barriers and drivers to adaptation to climate change-a field study of ten French local authorities. Clim Chang 155(4):621-637

Statistics Netherlands (2019) Figures. https://wwwcbsnl/en-gb/figures Accessed (04 June 2019) 
Swedish National Heritage Board, RAA (2019) Kulturarv i ett förändrat klimat. Handlingsplan för klimatanpassning 2019-2023 http://raadiva-portalorg/smash/get/diva2:1430464/FULLTEXT01pdf Accessed July 012020

Tansey E (2015) Archival adaptation to climate change. Sustainability: Science, Practice and Policy 11(2):45-56

UNESCO (2003) Convention for the safeguarding of the intangible cultural heritage. https://ichunescoorg/en/convention Accessed September 052019

United Nations Educational, Scientific and Cultural Organization, UNESCO (2017) Operational guidelines for the implementation of the World Heritage Convention. https://whcunescoorg/document/163852 Accessed September 052019

Van Alphen S (2020) Room for the river: innovation, or tradition? The case of the Noordwaard. In: Hein C (ed) Adaptive strategies for water heritage. Springer, Cham, pp 308-323

Van den Hurk B, Siegmund P, Klein Tank A (2014) KNMI'14: climate change scenarios for the 21st century, a Netherlands perspective. KNMI, De Bilt

Vojinovic Z, Hammond M, Golub D, Hirunsalee S, Weesakul S, Meesuk V, Medina N, Sanchez A, Kumara S, Abbott M (2016) Holistic approach to flood risk assessment in areas with cultural heritage: a practical application in Ayutthaya, Thailand. Nat Hazards 81:589-616

Wellstead A, Biesbroek R, Cairney P, Davidson D, Dupuis J, Howlett M et al (2018) Comment on "barriers to enhanced and integrated climate change adaptation and mitigation in Canadian forest management". Can J For Res 48(10):1241-1245

Xiao X, Seekamp E, Eaton M, Van der Burg MP, Fatorić S, McCreary A (2019) Optimizing historic preservation under climate change: decision support for cultural resource adaptation planning in National Parks. Land Use Policy 83:379-389

Publisher's note Springer Nature remains neutral with regard to jurisdictional claims in published maps and institutional affiliations. 